\title{
USO DE FÓRMULAS DE TRATAMIENTO \\ EN PUESTOS DE ATENCIÓN AL PÚBLICO DEL DOMINIO EDUCATIVO EN ESPAÑOL BONAERENSE
}

\author{
GiSELE GRACIELA JULIÁN \\ Universidad Nacional del Sur \\ Consejo Nacional de Investigaciones Científicas y Técnicas de Argentina
}

\section{INTRODUCCIÓN}

La dinámica de las fórmulas de tratamiento ha sido ampliamente estudiada en los últimos años en distintas comunidades, considerando contextos de uso, tanto institucionales como no institucionales. Precisamente, muchas investigaciones han puesto de relieve su importancia como elementos dinamizantes de la (des)cortesía verbal en diferentes dominios de interacción, tales como la interacción cotidiana o la desarrollada en encuentros de servicio de tipo comercial o institucional. Entre otros, podemos mencionar los aportes de Rigatuso ${ }^{1}$,

${ }^{1}$ Por ejemplo, E. M. Rigatuso, «Cortesía, tratamientos e identidad cultural en encuentros de servicio en español bonaerense», en M. del C. Vaquero y M. N. Cernadas de Bulnes (eds.), Actas de las II Jornadas Interdisciplinarias del Sudoeste Bonaerense, Archivo de la Memoria, UnS, Bahía Blanca, 2003, págs. 157-179; de la misma autora, «Cuestiones de variación lingüística en un sistema de tratamientos del español de la Argentina. El español bonaerense 1: extensiones metafóricas de términos de parentesco filiales», en Boletín de la Academia Argentina de Letras, Buenos Aires, LXXI, 2016, págs. 87-150; «Cuestiones de variación lingüística en un sistema de tratamientos del español de la Argentina. El español bonaerense 2: cambios momentáneos de tratamiento pronominal y esquemas innovadores», en Boletín de la Academia Argentina de Letras, Buenos Aires, 2017, págs. 309-366.

AnMal, XL, 2018-2019, págs. 163-196 
Placencia $^{2}$, Ferrer $^{3}$ y nuestras propias investigaciones ${ }^{4}$, que ponen en foco de atención tanto el uso lingüístico en marcos concretos como la percepción de los hablantes respecto de distintos fenómenos de (des)cortesía, entre los que destacan las fórmulas de tratamiento.

En este trabajo, que forma parte de una investigación ${ }^{5}$ sobre la expresión y percepción de la (des)cortesía en instituciones del dominio de la salud y la educación en la variedad dialectal del español bonaerense, proponemos analizar el uso de las fórmulas de tratamiento en las interacciones desarrolladas entre empleados y usuarios en instituciones del dominio educativo, considerando las distintas instancias de aparición en los intercambios con el fin de relevar en qué medida contribuyen a la expresión de la (des)cortesía en esos dominios. La comunidad objeto de estudio es una ciudad perteneciente a la región lingüística del español bonaerense. Los puestos de atención al público estudiados corresponden a: una institución educativa pública de nivel superior, una privada y una institución del ámbito educativo en la que los docentes realizan trámites.

La investigación se enmarca en un enfoque de Sociolingüística interaccional ${ }^{6}$, con aportaciones de Etnografía de la comunicación 7 , Microsociología de Goffman ${ }^{8}$ y Análisis del discurso9. Para el estudio de los fenómenos de

${ }^{2}$ M. E. Placencia, «Percepciones y manifestaciones de la (des)cortesía en la atención al público: el caso de una institución pública ecuatoriana», Oralia. Análisis del discurso oral, 4, 2001, págs. 213-241.

${ }^{3}$ M. C. Ferrer, «El discurso de la cortesía en puestos de atención al público en Argentina», en D. Bravo (ed.), Actas del Primer coloquio del programa EDICE, Universidad de Estocolmo, 2003, págs. 315-331.

${ }^{4}$ G. Julián, «Expresión y evaluación de la (des)cortesía en puestos de atención al público: análisis de casos en una institución pública del ámbito educativo bahiense», en A. Martínez y A. Speranza (eds.), Rumbos sociolingüísticos, Editorial FFyL-UnCuyo y SAL, Mendoza, 2013, págs. 53-71.

${ }^{5}$ La investigación, correspondiente a una tesis de Doctorado en Letras con orientación en Lingüística de la UNS, contó con el apoyo de sucesivas Becas Internas de CONICET desarrolladas bajo la dirección de la Dra. Elizabeth M. Rigatuso, y se inserta en un Proyecto de grupo de investigación dirigido por la Dra. Rigatuso («Estilo(s) comunicativo(s) y variación pragmática en la interacción verbal del español bonaerense: construcción de identidades, valores y creencias», subsidiado por la Secretaría de Ciencia y Tecnología de la Universidad Nacional del Sur).

${ }^{6}$ Véase J. Gumperz (ed.), Discourse strategies, Cambridge University Press, Nueva York, 1982; del mismo autor Language and social identity, Cambridge University Press, Nueva York, 1982; «Interactional Sociolinguistics: A Personal Perspective», en D. Schiffrin, D. Tannen y H. Hamilton (eds.), The Handbook of Discourse Analysis, MA, Blackwell, Malden, 2001, págs. 215-228; D. Tannen, Conversational style. Analizing talk among friends, Ablex publishing corporation, Nueva Jersey, 1985; Género y discurso, Paidós, Barcelona, 1996; «Interactional Sociolinguistics», en U. Ammon et alii (eds.), Sociolinguistics: An International Handbook, Walter de Gruyter, Berlín, 2004.

7 J. Gumperz, J. y Dell Hymes (eds.), Directions in sociolingüistics. The ethnography of communication, Holt, Rinehart and Winston, Inc, Nueva York, 1972.

${ }^{8}$ E. Goffman, Interaction ritual. Essays on face to face behaviour, Doubleday Anchor Books, Nueva York, 1967.

${ }_{9}$ P. Drew y M. Sorjonen, «Diálogo institucional», en T. Van Dijk (comp.), El discurso como interacción social. Estudios sobre el discurso II. Una introducción multidisciplinaria, Gedisa Editorial, Barcelona, 2000. 
cortesía seguimos la Pragmática sociocultural ${ }^{10}$. En lo relativo a las fórmulas de tratamiento son referentes los postulados de Brown y Gilman ${ }^{11}$ y las aportaciones de Rigatuso ${ }^{12}$ en sus estudios sobre español bonaerense. En el análisis seguimos el modelo de estructura conversacional que aplica Rigatuso en sus estudios sobre la dinámica interaccional de las fórmulas de tratamiento en el español bonaerense en la interacción comercial de la variedad ${ }^{13}$, elaborado sobre pautas básicas de organización interactiva del discurso: la estructura postulada por Teun van Dijk ${ }^{14}$.

A continuación ofrecemos un apartado en el que se detalla la metodología empleada en esta investigación y luego se presentan algunas consideraciones teóricas sobre las fórmulas de tratamiento. El análisis se divide en un apartado

${ }^{10}$ Véanse al respecto D. Bravo, «¿Imagen 'positiva' vs. Imagen 'negativa’? Pragmática sociocultural y componentes de face», Oralia. Análisis del discurso oral, 2, 1999, págs. 155-184; D. Bravo y A. Briz (eds.), Pragmática sociocultural. Estudios sobre cortesía en español, Ariel, Barcelona, 2004; S. Kaul, «Tipología del comportamiento verbal descortés en español», en Actas del III Coloquio Internacional del Programa EDICE, Universidad de Valencia, 2008, págs. 254-266; de la misma autora «Perspectiva topológica de la descortesía verbal. Comparación entre algunas comunidades de práctica de descortesía del mundo hispanohablante», en F. Orletti y L. Mariottini (eds.), (Des)cortesía en español. Espacios teóricos y metodológicos para su estudio, Università degli Studi Roma Tre- EDICE, Roma / Estocolmo, 2010, págs. 71-86.

${ }^{11}$ R. Brown y A. Gilman, «The pronouns of power and solidarity», en T. Sebeok (ed.), Style in Language, Massachusetts Institute of Technology, Nueva York, 1960, págs. 253-275.

${ }^{12}$ E. Rigatuso, «Cortesía, tratamientos e identidad cultural en encuentros de servicio en español bonaerense», en M. Vaquero y M. Cernadas de Bulnes (eds.), Actas de las II Jornadas Interdisciplinarias del Sudoeste Bonaerense, Archivo de la Memoria, uns, Bahía Blanca, 2003, págs. 157-179; de la misma autora «“ ¿Y vos por qué me tratás de usted?” Fórmulas de tratamiento y cortesía lingüística en español bonaerense actual», en Actas del X Congreso de la Sociedad Argentina de Lingüística, Universidad Católica de Salta / Sociedad Argentina de Lingüística, Salta, 2006, págs. 1-23; “'Madryn, pasame el apunte’. Aspectos léxico-semánticos del vocativo en español bonaerense actual», en M. Cernadas y J. Marcilese (eds.), Politica, sociedad y cultura en el Sudoeste Bonaerense, Actas de las V Jornadas Interdisciplinarias del Sudoeste Bonaerense, Ediuns, Bahía Blanca, 2009, págs. 369-386; «Funciones sociolingüísticas y pragmáticas de las fórmulas de tratamiento en español: consideraciones sobre la variedad bonaerense», conferencia presentada en el XIV Congresso Brasileiro de Professores de Espanhol, Niteroi, Brasil, 2011; «Interacción, variación y cambio: estrategias comunicativas en la interacción comercial del español bonaerense actual», en S. Martín Menéndez (coord.), Actas de las II Jornadas Internacionales Beatriz Lavandera: sociolingüistica y análisis del discurso, Editorial de la FFyL UBA, Buenos Aires, 2015, págs. 1437-1470.

${ }_{13}$ Por ejemplo, E. M. Rigatuso, «Dinámica de los tratamientos en la interacción verbal: preparación y apertura conversacionales», Anuario de Lingüistica Hispánica III, Universidad de Valladolid, Valladolid, 1987, págs. 161-182; de la misma autora «'Señora [...] ¿No tenés más chico?' Un aspecto de la pragmática de las fórmulas de tratamiento en español bonaerense», Revista Argentina de Lingüística, 16, 2000, págs. 293-344; «¿Cortesías en pugna? Fórmulas de tratamiento nominales y (des)cortesía verbal en encuentros de servicio comerciales del español bonaerense actual», ponencia presentada en XI Congreso Internacional ALED, Instituto de Lingüística, Facultad de Filosofía y Letras, Universidad de Buenos Aires, 2015.

${ }^{14}$ T. Van Dijk, La ciencia del texto, Paidós, Buenos Aires, 1983, págs. 276-280. 
sobre usos generales, contemplando las distintas instancias de la interacción en las que se registran las fórmulas, y un apartado sobre usos específicos registrados en una institución en particular, incluyendo en este último caso las percepciones de los usuarios y hablantes de la comunidad sobre las fórmulas que les dispensan los empleados. Finalmente, el último apartado presenta las conclusiones a las que arribamos a partir del análisis.

\section{Metodología}

De acuerdo con el marco teórico señalado, la investigación se realiza siguiendo los lineamientos metodológicos de la Sociolingüística ${ }^{15}$, en particular en su vertiente de Sociolingüística interaccional, dentro de la propuesta de Gumperz ${ }^{16}$, de la Antropología lingüística ${ }^{17}$ y de la Pragmática sociocultural ${ }^{18}$.

Dentro del conjunto amplio y variado existente de puestos de atención al público hemos realizado un recorte orientado por observaciones previas efectuadas como miembro de la comunidad. Los puestos de atención al público han sido seleccionados según el interés y la complejidad advertidos en el estudio exploratorio. Como hemos anticipado, estos corresponden a una institución educativa pública, una institución educativa privada, ambas de nivel superior, y una institución del ámbito educativo en la que los docentes realizan diversos trámites relacionados con la labor docente. En el caso de la institución educativa pública se escogieron, a su vez, dos puestos de atención que corresponden, por un lado, a ventanillas y escritorios de una dependencia dedicada a la atención de trámites de alumnos de la institución en general, y por otro, a puestos de un Departamento Académico específico - el equivalente a una facultad en la estructura universitaria - donde se atiende tanto a alumnos como a docentes. En relación a la institución privada, hemos analizado las interacciones desarrolladas en el único puesto de atención al público que posee, una ventanilla de la oficina administrativa en la que atienden a docentes y alumnos actuales o potenciales. En el conjunto de dichos puestos

15 Véase W. Labov, «The study of language in its social context», Studium Generale, 23, 1970, 30-87; F. Moreno Fernández, Metodología sociolingüística, Gredos, Madrid, 1990; H. López Morales, Métodos de investigación lingüistica, Editorial del Colegio de España, Salamanca, 1994; J. M. Hernández Campoy y M. Almeida, Metodología de la investigación sociolingüística, Editorial Comares, Málaga, 2005.

16 J. Gumperz, Discourse strategies; véase del mismo autor Language and social identity; «Interactional Sociolinguistics: A Personal Perspective».

${ }^{17}$ A. Duranti, Antropología lingüistica, Cambridge University Press, Madrid, 2000.

${ }^{18}$ Por ejemplo, D. Bravo, «¿Imagen 'positiva' vs. Imagen 'negativa'? Pragmática sociocultural y componentes de face»; «Pragmática, sociopragmática y pragmática sociocultural del discurso de la cortesía. Una introducción», en D. Bravo, N. Hernández Flores y A. Cordisco (eds.), Aportes Pragmáticos, sociopragmáticos y socioculturales a los estudios de la cortesía en español, Dunken, Estocolmo-Bs. As., 2009, págs. 31-68; D. Bravo y A. Briz (eds.), Pragmática sociocultural. Estudios sobre cortesía en español, Ariel, Barcelona, 2004. 
de atención al público se realizan trámites vinculados con solicitudes de certificados (analíticos, de alumno regular, de título en trámite, etc.), solicitudes de títulos, retiro de recibos de sueldo, entrega de planillas, consultas y reclamos sobre temas específicos de las distintas carreras o materias. Por otra parte, hemos seleccionado una institución educativa pública a la que concurren docentes y estudiantes de carreras vinculadas a la docencia para realizar diversos trámites y consultas relacionados con dicha labor. En ese caso, hemos escogido puestos de atención al público de dos oficinas en las que los empleados atienden en escritorios.

Para la conformación del corpus se emplea una combinación de técnicas de trabajo de campo de carácter etnográfico orientadas a relevar uso y percepción. En relación con el uso concreto, aplicamos la técnica de participante-observador, mientras que para relevar la percepción de los usuarios aplicamos tests de hábitos sociales y realizamos experiencias con usuarios-jueces que actúan como evaluadores de algunas interacciones. En este trabajo abordamos concretamente el uso de las fórmulas de tratamiento, aunque hacemos algunas referencias a las percepciones de los usuarios cuando el análisis lo requiere.

Como hemos anticipado, con el fin de relevar el uso concreto utilizamos la técnica de participante-observador ${ }^{19}$ en sus distintos modos de realización: participante-observador y observador no participante ${ }^{20}$. En el primer caso, procedemos al registro de interacciones naturales producidas en los contextos estudiados en las que la investigadora participa activamente. En el caso de observador no participante, la aplicación de la técnica consiste en acompañar durante la consulta o el trámite a usuarios que nos prestan su colaboración, sin intervenir la investigadora activamente en la interacción, y en la toma de datos de interacciones producidas por otros hablantes en esos dominios. La mayoría de las interacciones han sido grabadas, manteniendo el anonimato de los participantes como parte del compromiso ético de este tipo de investigaciones ${ }^{21}$, y luego transcriptas siguiendo las convenciones de transcripción incluidas en Van Dijk $^{22}$ e ideadas por Gail Jefferson ${ }^{23}$. Además se tomaron notas etnográficas.

19 W. Labov, «The study of language in its social context», Studium Generale, 23, 1970, págs. 30-87; J. Gumperz, Discourse strategies, op. cit.

${ }^{20}$ F. Moreno Fernández, Metodología sociolingüística, Gredos, Madrid, 1990.

${ }^{21}$ B. Gabbiani y I. Madfes (org.), Conversación y Poder. Análisis de interacciones en aulas y consultorios, Fondo Clemente Estable, Universidad de la República, Montevideo, 2006.

${ }^{22}$ T. Van Dijk (comp.), El discurso como interacción social. Estudios sobre el discurso II. Una introducción multidisciplinaria, Gedisa Editorial, Barcelona, 2000.

${ }^{23}$ [ ] : Simultaneidad de emisiones o fragmentos de emisiones.

:::: $\quad$ Alargamiento de la sílaba previa.

MAYÚSCULAS: $\quad$ Mayor volumen de emisión o fragmentos de emisión.

Símbolos de grado: Suavidad o amplitud disminuida de emisiones incluidas.

Subrayado: $\quad$ Énfasis mayor en la emisión del hablante.

Signo igual $=\quad$ No transcurrió tiempo entre los objetos conectados por elsigno. Significa que el hablante siguiente inicia su emisión al final de la emisión del hablante actual. 
Se registraron 150 interacciones entre los años 2011 y 2015, lo que representan un total de 15 horas aproximadas de grabación. A eso se suman las interacciones y fragmentos que no han sido grabados pero que se registraron a partir de la toma de notas. La duración de las interacciones, que puede fluctuar entre un minuto y 30 minutos aproximadamente, varía de acuerdo con la índole del trámite o consulta.

A fin de relevar la percepción de los hablantes de la comunidad sobre los fenómenos objeto de estudio, y siguiendo la propuesta metodológica que a tal fin propone la Pragmática sociocultural para el relevamiento de las percepciones, aplicamos cuestionarios a los usuarios de las instituciones estudiadas. Hemos trabajado con test de hábitos sociale ${ }^{24}$ con el fin de analizar las actitudes y percepciones de los usuarios con respecto a las cuestiones interaccionales bajo estudio ${ }^{25}$. La muestra correspondiente al test aplicado a usuarios del ámbito educativo está conformada por 30 hablantes anónimos de la comunidad, y se encuentra equilibrada según las variables de sexo y edad: hombres y mujeres comprendidos en tres franjas etarias (entre 18 y 34 años, entre 35 y 59 y mayores de 60 años). Dada la índole de las instituciones estudiadas, hemos seleccionado informantes de nivel educacional alto. El test se distribuyó por escrito mediante correo electrónico y en papel.

Siguiendo la propuesta metodológica de Gumperz ${ }^{26}$, realizamos experiencias con usuarios-jueces, que consisten en presentar a algunos usuarios fragmentos de interacciones grabadas y su transcripción, para que ellos actúen como jueces

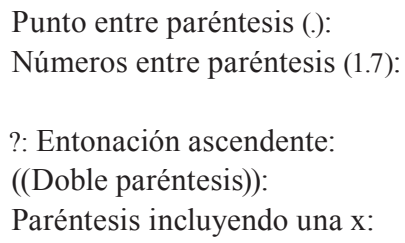

Cursiva:
Pausa de una décima de segundo.

Segundos y décimas de segundos entre turnos de los hablantes o dentro de un mismo turno.

Entonación interrogativa.

Aclaraciones, descripciones.

(x)Detención repentina o vacilación por parte del hablante.

Emisión representativos de los usos y fenómenos analizados.

${ }^{24}$ En D. Bravo (ed.), Actas del Primer coloquio del programa EDICE: D. Bravo, «Actividades de cortesía, imagen social y contextos socioculturales: una introducción», págs. 98-108; D. Bravo, «Pragmática, sociopragmática y pragmática sociocultural del discurso de la cortesía. Una introducción»; S. Boretti, «Tests de hábitos sociales y la investigación de la cortesía», págs. 198-202; y N. Hernández Flores, «Los tests de hábitos sociales y su uso en el estudio de la cortesía: una introducción», págs. 186-197; en J. Murillo Medrano (ed.), Actas del II Coloquio Internacional del Programa EDICE, Universidad de Costa Rica y Universidad de Estocolmo, 2005: J. Murillo Medrano, «Significados de la cortesía lingüística a partir de la aplicación de un test de hábitos sociales en Costa Rica», págs. 115-136; en A. Briz et alii (eds.), Actas del III Coloquio Internacional del Programa EDICE, Universidad de Valencia, 2008: M. Bernal, «El test de hábitos sociales aplicado al estudio de la descortesía», págs. 623-641; y J. Contreras Fernández, «Test de hábitos sociales en un análisis contrastivo sobre el uso y la interpretación de la cortesía lingüística», págs. 642-656.

${ }^{25}$ M. E. Placencia, op. cit., págs. 213-241.

${ }^{26}$ J. Gumperz (ed.), Discourse strategies. 
o evaluadores de dichas interacciones $\mathrm{y}$, en relación con nuestro objeto de análisis, detecten expresiones de (des)cortesía y la presencia posible de problemas de comunicación que incidan en la comprensión.

Para esta experiencia hemos tomado una muestra poblacional equilibrada según las variables de sexo, edad y nivel socioeducacional, que incluye hombres y mujeres, de nivel educacional Alto [A] (terciario universitario y no universitario), Medio [M] (secundario) y Bajo [B] (primario), comprendidos en las tres franjas etarias mencionadas. En los casos puestos a consideración hemos seleccionado 18 hablantes de la comunidad de acuerdo con dichas variables.

En el procesamiento de los datos tenemos en cuenta distintas variables sociodemográficas (sexo, edad, nivel socioeducacional) y contextuales ${ }^{27}$ (estilos según contextos situacionales e imagen personal que se desea proyectar), además del tipo de institución a la que pertenece la interacción (variable institución pública/ institución privada) y la relación existente entre los hablantes, considerando las dimensiones de poder y solidaridad propuestas por Brown y Gilman ${ }^{28}$.

\section{LA DINÁMICA DE LAS FÓRMULAS DE TRATAMIENTO EN PUESTOS DE ATENCIÓN AL PÚBLICO DEL DOMINIO EDUCATIVO}

Las fórmulas de tratamiento constituyen un fenómeno de especial interés en los estudios sobre cortesía verbal. Seguimos los postulados de Rigatuso, que las define en los siguientes términos:

Las lenguas de distintas comunidades del mundo poseen en sus sistemas lingüísticos un conjunto de formas para dirigirse al destinatario y hacer referencia a una tercera persona y a sí mismos en el discurso. Estas formas, que comprenden el uso concertado en la interacción lingüística de elementos nominales, pronominales y verbales, han recibido la designación de fórmulas de tratamiento ${ }^{29}$.

De acuerdo con la investigadora, las fórmulas de tratamiento comprenden, además de su uso como vocativo, su empleo como referencial, que incluye la alusión a una tercera persona, la autorreferencia y un uso genérico de las formas nominales para aludir a determinados grupos humanos ${ }^{30}$.

${ }_{27}$ J. M. Hernández Campoy y M. Almeida, op. cit.

${ }^{28}$ R. Brown y A. Gilman, op. cit.

${ }^{29}$ E. M. Rigatuso, «Fórmulas de tratamiento, políticas lingüísticas y actitudes en el español de la Argentina: El caso del español bonaerense», en G. Kremnitz y J. Born (comps.), Lenguas, Literaturas y sociedad en la Argentina. Diálogos sobre la investigación en Argentina, Uruguay y en países germanófobos, Actas del coloquio, Edition Praesens, Universidad de Viena, 2004, pág. 197.

${ }^{30}$ E. M. Rigatuso, «Pasado y presente en el sistema de tratamientos del español bonaerense. De la gramática a la pragmática en el español regional», en La lengua española: sus 
Tal como señala Rigatuso, dichas formas funcionan «como marcadores lingüísticos de relaciones interpersonales de los hablantes —donde rigen las dimensiones de poder y solidaridad (Brown y Gilman 1960) - , y marcadores sintomáticos de identidad...» $\rangle^{31}$. La investigadora define también el concepto de pauta de uso o esquema de trato en los siguientes términos:

[...] el empleo concertado, en el discurso y en el sistema, de las diferentes categorías que integran el sistema de tratamientos en español: elementos nominales, pronominales y verbales. Esta co-ocurrencia de elementos define y expresa, en su articulación, el tipo de vínculo que une a los hablantes en términos de simetría y asimetría de las relaciones ${ }^{32}$.

Asimismo, los tratamientos cumplen una función fundamental en la manifestación de la cortesía verbal, tanto en su vertiente normativa como estratégica $^{33}$. En cuanto a los valores comunicativos de las fórmulas de tratamiento, Rigatuso señala:

Las fórmulas de tratamiento desempeñan un papel fundamental en diferentes instancias de la comunicación verbal, ya sea por su presencia frente a su ausencia, o por los variados matices pragmáticos y estilísticos que en su uso actualizan. Estos usos y valores comunicativos, que hacen a su dinámica interactiva, comprenden —entre otros- los siguientes aspectos: expresión del conocimiento de los participantes respecto del papel y estado que poseen en un contexto concreto de uso lingǘstico (Lyons, 1980: 516-517), manifestación de cortesía y deferencia explícita, expresión lingüística de afecto, exaltación emocional pasajera o joco-sidad, y el papel estratégico que cumplen los tratamientos en la organización y mecánica del discurso, que adquiere particular relevancia en la conversación, con funciones fundamentales en distintas instancias nucleares - por ejemplo- en las instancias estructurales iniciales de preparación y apertura, y final de terminación, así como, en la microestructura, en distintos tipos de pares de adyacencia y en la asignación de turnos en una conversación ${ }^{34}$.

variantes en la región. Primeras Jornadas Académicas Hispanorrioplatenses sobre la lengua española, Academia Argentina de Letras, Buenos Aires, 2008, págs. 183-199.

${ }^{31}$ E. M. Rigatuso, «Fórmulas de tratamiento, políticas lingüísticas y actitudes en el español de la Argentina: El caso del español bonaerense».

32 E. M. Rigatuso, «Cuestiones de variación lingüística en un sistema de tratamientos del español de la Argentina. El español bonaerense 2: cambios momentáneos de tratamiento pronominal y esquemas innovadores».

${ }^{33}$ E. M. Rigatuso, «Fórmulas de tratamiento, políticas lingüísticas y actitudes en el español de la Argentina: El caso del español bonaerense».

${ }^{34}$ E. M. Rigatuso, «Cortesía, tratamientos e identidad cultural en encuentros de servicio en español bonaerense». 
Así, en muchos ámbitos de interacción en la comunidad bahiense, tales como la conversación compra/venta, las fórmulas de tratamiento nominales desempeñan un papel fundamental en distintas instancias de la interacción - como la apertura conversacional, la fase de preparación conversacional de la compra/venta, las instancias de orientación, objeto de la conversación y conclusión - en las que el vendedor las usa al dirigirse al cliente para expresar cortesía y amabilidad, y dar cumplimiento a necesidades operativas en este tipo de interacción ${ }^{35}$. Por nuestra parte, en las instituciones objeto de estudio no se observa un uso tan frecuente de dichas formas, y suelen registrarse interacciones completas en las que ninguno de los participantes recurre al uso de fórmulas de tratamiento. Su aparición, por lo tanto, resulta particularmente significativa en estos contextos. A lo largo del corpus se registran usos, algunos de ellos muy interesantes y creativos, en boca de los empleados en distintas instancias de las interacciones.

En cuanto a los tipos y subtipos de tratamientos empleados en las instancias en las que se verifica su aparición, las fórmulas elegidas por los empleados pertenecen a los siguientes tipos dentro del subsistema correspondiente del español bonaerense, según las categorías establecidas por Rigatuso ${ }^{36}$ : a) nombres de pila, b) términos de parentesco empleados metafóricamente en lo que se denomina usos ficticios ${ }^{37}$ de los términos de parentesco (por ejemplo, madre, mamita, $m a$ ), c) términos de amistad, cordialidad y afecto (por ejemplo, corazón, mi amor, mi vida, querida), y d) términos sociales de índole general: formas destinadas a niños (por ejemplo, chicos-as, niño- $a$, nena) y destinadas a adultos (por ejemplo, señor, señora, señorita, muchacho).

En cuanto al uso pronominal, los empleados eligen generalmente el pronombre de confianza vos + sus formas verbales correspondientes para dirigirse a los usuarios, que en esas instituciones suelen ser personas jóvenes, en el caso de los alumnos, o docentes jóvenes y de edad mediana o mayor que suelen tener una relación de confianza con los empleados por la frecuencia de trato. En algunos casos se ha registrado asimismo la forma usted para dirigirse a docentes de edad mayor.

Por su parte, los usuarios de estas instituciones suelen elegir el pronombre de confianza vos + sus formas verbales para dirigirse a los empleados más jóvenes, mientras que hacia los empleados de mayor edad registramos el pronombre formal usted + sus formas verbales. Asimismo, los usuarios no suelen utilizar fórmulas de tratamiento nominales en uso vocativo con los empleados,

35 E. M. Rigatuso, loc. cit.

36 Véase E. M. Rigatuso, Fórmulas de tratamiento y familia en el español bonaerense actual, Universidad Nacional del Sur, Bahía Blanca, 1994, pág. 21; de la misma autora, «'Señora [...] ¿No tenés más chico?' Un aspecto de la pragmática de las fórmulas de tratamiento en español bonaerense».

37 F. Braun, Terms of Address.Problems of patterns and usage in various languages and cultures, Mouton de Gruyter, Berlin-New York-Amsterdam, 1988, en E. M. Rigatuso, «Cuestiones de variación lingüística en un sistema de tratamientos del español de la Argentina. El español bonaerense 1: extensiones metafóricas de términos de parentesco filiales». 
más allá de algunos ejemplos recogidos en nuestro corpus de la forma señora para las empleadas de mayor edad. Más frecuente resulta el uso del nombre de pila del empleado como forma de tratamiento nominal, aunque dicho uso se registra especialmente en los casos en los que existe un conocimiento previo entre los interactuantes.

El análisis que presentamos a continuación se organiza en dos partes: la primera se refiere a los usos generales relevados en los distintos puestos de atención del dominio educativo, mientras que la segunda aborda el análisis de los usos registrados en un contexto específico.

\subsection{Usos generales}

Entre las fórmulas de tratamiento nominales cuyo uso hemos relevado en las instituciones del ámbito educativo estudiadas, ocupan un lugar destacado los nombres de pila o sobrenombres. Estos usos se registran en dos situaciones: aquellas interacciones en las que existe un conocimiento previo entre los participantes y aquellas en las que tal conocimiento no existe. En los casos en que los interactuantes se conocen, ya sea porque el usuario es docente de la institución o un alumno que hace tiempo que estudia allí, lo que implica una asidua recurrencia a algunas ventanillas y la consiguiente identificación mutua, suele ocurrir con frecuencia que tanto empleados como usuarios utilicen, en alguna instancia de la interacción, el nombre de pila, sobrenombre o forma diminutiva del nombre de su destinatario, dependiendo del grado de conocimiento mutuo y de la confianza en el vínculo ${ }^{38}$. Dichos usos fueron relevados especialmente en las instancias de apertura y cierre conversacional, junto a los saludos de inicio y de despedida, y acompañando agradecimientos, así como también en instancias intermedias para focalizar en el interlocutor en la formulación de preguntas o pedidos.

Por otra parte, especialmente cuando no existe conocimiento previo entre los participantes, en distintas instancias de los intercambios hemos relevado el uso de otras fórmulas de tratamiento nominales distintas del nombre de pila, correspondientes a la categoría Términos sociales de indole general ${ }^{39}$, tales como formas destinadas a niños (por ejemplo, chicos-as) y términos generales destinados a adultos (por ejemplo, señor, señora, señorita, muchacho).

A continuación presentamos el análisis del uso de fórmulas de tratamiento de acuerdo con la instancia de la interacción en la que aparecen.

\subsubsection{Instancia de apertura}

Tal como postula Rigatuso, el uso de tratamientos en la instancia de apertura conversacional ofrece particular interés dada su funcionalidad pragmática y

\footnotetext{
${ }^{38}$ Cf. E. M. Rigatuso, Fórmulas de tratamiento y familia en el español bonaerense actual.

39 Véase E. M. Rigatuso, loc. cit.
} 
los valores expresivos que manifiestan ${ }^{40}$. Al respecto, entre los usos y funciones de los tratamientos en español bonaerense en esta instancia conversacional recoge los siguientes: a) Registro de un tratamiento nominal en las expresiones de apertura conversacional, y b) Fórmula + entonación específica como reemplazo de toda una oración, en la apertura del intercambio verbal entre empleado y cliente de un comercio o institución. Ambas funciones se registran en los dominios que analizamos. En ese marco, a continuación nos referimos a los distintos usos que relevamos en nuestro corpus:

a) Registro de un tratamiento nominal en las expresiones de apertura conversacional

- Nombre de pila:

Como hemos anticipado, resulta frecuente en estas instituciones el uso del nombre de pila del destinatario en boca de empleados y de usuarios acompañando una fórmula de saludo, en los casos en que existe conocimiento previo por la frecuencia de trato. A continuación transcribimos algunos fragmentos de interacciones que tienen lugar en cada una de las instituciones del ámbito educativo objeto de estudio, en los que registramos usos de los nombres de pila, sobrenombres o apócopes tanto por parte de los empleados hacia los usuarios como de estos últimos hacia los empleados:
(1) EMISOR
Empleado
DESTINATARIO (hombre-35 años)
Usuario (mujer-28 años)

Contexto: En una institución educativa pública de nivel superior, la usuaria [U] se acerca a la ventanilla a realizar una consulta sobre la inscripción a un seminario de posgrado:

- [E] hola (.) qué tal?

— [U] hola qué tal ariel (.) cómo estás? (.) para inscribirme en el seminario de posgrado de sociología?
(2) EMISOR
Empleado

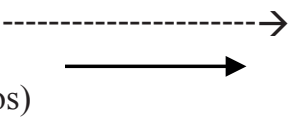
DESTINATARIO
Usuario
(mujer-28 años)
(mujer-64 años)

Contexto: La empleada [E] de una institución educativa pública de nivel superior termina de atender a una usuaria y se dirige a la siguiente usuaria, una profesora de esa universidad:

- [E] hola norma!
(3) EMISOR
Empleado
DESTINATARIO
(mujer-35 años)
Usuario
(mujer-29 años)

Contexto: En una institución educativa privada de nivel superior, E se dirige a $U$, docente de dicha institución:

- [E] cómo vas ceci?

- $[\mathrm{U}]$ hola mari (.) justo tenía que hablar con vos

${ }^{40}$ E. M. Rigatuso, «Dinámica de los tratamientos en la interacción verbal: preparación y apertura conversacionales», pág. 171. 

(4) EMISOR
Usuario

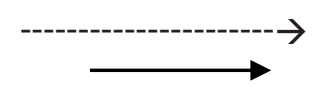
DESTINATARIO
(mujer-40 años)
Empleado
(hombre-40 años)

Contexto: En una institución pública del ámbito educativo en la que los docentes realizan diversos trámites, U se dirige a E para realizar una consulta:

- [U] hola mariano (.) tengo una duda sobre la inscripción

- Otras fórmulas nominales:

Asimismo, tanto empleados como usuarios utilizan la forma chicos-as para destinatarios plurales acompañando los saludos en la instancia de apertura y en la de preparación, como se observa en los siguientes ejemplos:

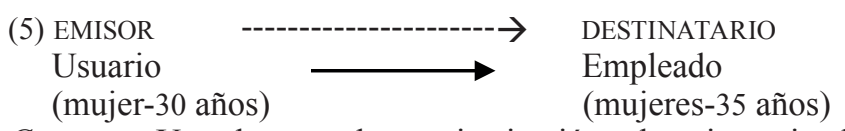

Contexto: Una docente de una institución educativa privada de nivel superior ingresa a la oficina de administración en la que se encuentran dos empleadas:

- $[\mathrm{U}]$ hola chicas $($.$) permiso$
(6) EMISOR $\quad--------------------\rightarrow \quad$ DESTINATARIO

Empleado $\longrightarrow \quad$ Usuario $1 \quad$ Usuario 2
(mujer-45 años)

Contexto: En una institución pública del ámbito educativo en la que los docentes realizan diversos trámites, u1 ingresa a una oficina a realizar una consulta y se acerca una empleada:

- [E] chicas qué necesitaban? buen [día]

- [U1] [ho:la] (.) buen día (.) me tengo que anotar en el listado oficial $\mathrm{y}$ tengo que agregar unos curso:s?

b) Fórmula + entonación especifica como reemplazo de toda una oración en la apertura del intercambio verbal entre empleado y usuario

Tal como señala Rigatuso en referencia a la interacción comercial e institucional en español bonaerense, resultan frecuentes usos elípticos que consisten en «fórmula + entonación específica como reemplazo de toda una oración, en la apertura del intercambio verbal entre empleado y cliente de un comercio o institución $»^{41}$. En esos casos, la fórmula con entonación específica sustituye emisiones como qué va (vas) a llevar/ qué necesita (necesitás). Se trata de formas utilizadas por los empleados para iniciar la interacción y señalarles a los clientes que ha llegado su turno ${ }^{42}$.

En la instancia de apertura conversacional de las instituciones estudiadas no hemos registrado un uso frecuente de fórmulas de tratamiento nominal, ya que lo más común es que en esta instancia el empleado solo mire al usuario o

\footnotetext{
${ }^{41}$ E. M. Rigatuso, loc. cit., pág. 177.

${ }^{42}$ E. M. Rigatuso, loc. cit., págs. 177-178.
} 
lo salude sin utilizar fórmulas de tratamiento. Sin embargo, en estos dominios registramos, además de los usos mencionados en la función anterior para la instancia de apertura, usos aislados de la fórmula nominal muchacho? con entonación específica y de la forma pronominal vos? como inicio de interacción, en la función señalada de reemplazo de toda una oración en la apertura del intercambio verbal entre empleado y usuario. A continuación transcribimos ejemplos de estos usos:

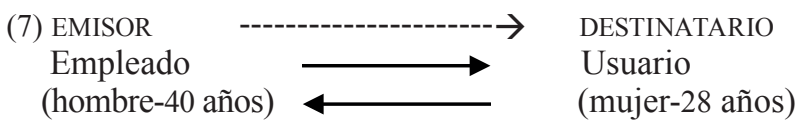

Contexto: Un empleado de una institución educativa pública de nivel superior atiende a un usuario que va a sacarse una foto para un trámite y E le pide que espere en el pasillo. A continuación se dirige a la siguiente usuaria de la fila:

- [E] vos?

- [U] ho:la qué tal? también para sacarme la foto
(8) EMISOR Empleado

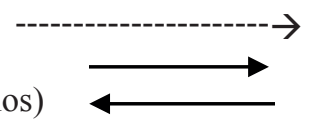
DESTINATARIO
Usuario
(mujer-45 años)
(mujer-25 años)

Contexto: En una institución educativa pública de nivel superior, E atiende a una usuaria que se dirige a su ventanilla para abonar un trámite. Mientras imprime la factura E se dirige a la usuaria que sigue en la fila:

- [E] sí (.) vos?

- [U] también por lo del título
(9) EMISOR
Empleado
DESTINATARIO (mujer-58 años)
Usuario
(mujer-28 años)

Contexto: La empleada de una institución pública del ámbito educativo en la que los docentes realizan diversos trámites termina de atender a otra usuaria y dirige su mirada a U:

- [E] vos?

- $[\mathrm{U}]$ hola (.) quería hacer una consul- ((se detiene porque E vuelve a responderle algo a la usuaria anterior))
(10) EMISOR
Empleado

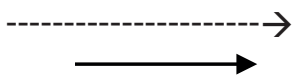
DESTINATARIO
Usuario
(hombre-35 años)
(hombre-28 años)

Contexto: U se dirige a una ventanilla de una institución educativa pública de nivel superior para realizar un trámite. E termina de atender a otro usuario y se dirige a U:

- [E] muchacho?

Asimismo, en instancias de apertura conversacional registramos, en boca de empleados al dirigirse a destinatarios plurales de edad joven, el uso de la fórmula nominal chicos-as + entonación de interrogación, fórmula que aparece 
además, como mostramos a continuación, en secuencias de cierre interaccional y saludos, y en instancias intermedias acompañando preguntas o comentarios, así como también en sus usos referenciales:
(11) EMISOR
Empleado

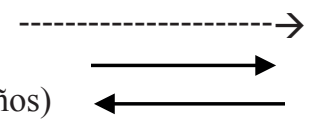
DESTINATARIO
(mujer-30 años)
Usuario
(mujeres-22 años)

Contexto: La empleada de una institución educativa privada de nivel superior se dirige a las usuarias que esperan en ventanilla:

- $[\mathrm{E}]$ chicasss?

\subsubsection{Instancias intermedias-fase transaccional}

Aunque no resultan de uso muy frecuente en todos los intercambios, en esta instancia de las interacciones relevamos el uso de tratamientos nominales que corresponden al nombre de pila del destinatario y a otras fórmulas nominales.

a) Nombre de pila

- Conocimiento previo:

Cuando los participantes se conocen mutuamente por la frecuencia de trato en los puestos de atención al público o por ser los usuarios docentes o alumnos avanzados de la institución, registramos el uso del nombre de pila para focalizar en el destinatario al realizar una pregunta o pedido. Los siguientes ejemplos ilustran estos usos:
Usuario
(mujer-31 años)
(12) EMISOR

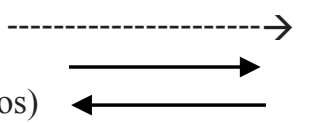
DESTINATARIO
Empleado
(mujer-30 años)

Contexto: La usuaria ingresa a la oficina de administración de una institución educativa privada de nivel superior en la que se desempeña como docente. Una hora antes ya había interactuado con la empleada:

- $[\mathrm{U}](($ entrando) $)$ permi::so

- [E] ((atendiendo a otra docente)) pasá pasá ((termina de atender a la otra docente y se dirige a U)) gabriela alcanzaste a corregir?

- [U] sí:: (1) todo
(13) EMISOR
Empleado

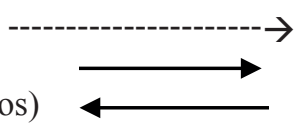
DESTINATARIO
Usuario
(mujer-55 años)

Contexto: En una institución educativa pública de nivel superior, U se dirige a una ventanilla del departamento en el que se desempeña como docente para realizar un trámite. Mientras espera que E le entregue documentación para firmar, U pregunta:

- $[\mathrm{U}]$ ale querés que: eh como la otra vez yo lo lleve? ((se refiere a una documentación))
(14) EMISOR
Empleado

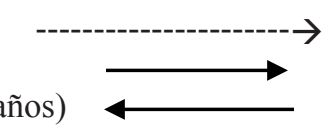
DESTINATARIO
Usuario
(mujer-30 años)
(mujer-31 años) 
Contexto: En una institución educativa privada de nivel superior la usuaria, docente de dicha institución, realiza una consulta y E le responde:

- [E] aguardame un segundito gisela que me fijo ((chequea datos en la computadora))

- Ausencia de conocimiento previo:

En los casos en los que no existe conocimiento previo y frecuencia de trato entre los participantes, es el empleado quien utiliza el nombre de pila del usuario cuando tiene acceso a este a través de la computadora o de alguna planilla con sus datos. Dicho uso, que acompaña el empleo del pronombre de confianza vos, contribuye a la personalización del discurso institucional. Los siguientes fragmentos de interacciones son ilustrativos de tales usos:
(15) EMISOR

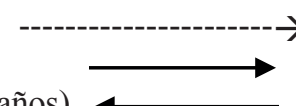
DESTINATARIO
Usuario
Empleado
(hombre-30 años)
(mujer-27 años)

Contexto: En una institución educativa pública de nivel superior, el usuario se ha retirado para completar un formulario. Al regresar a la ventanilla se produce la siguiente interacción:

- $[\mathrm{U}]$ te lo dejo nomás?

- [E] no no! te tengo que tomar todos los datos (5) esto es para pasar a retirar en febrero con un arancel de uno con cincuenta que lo abonás en el primer piso y el dni (.) sí? (5) ((mirando la computadora)) esta es la foto que te sacaste nicolás? es la última? ((mostrándole una foto de la computadora))

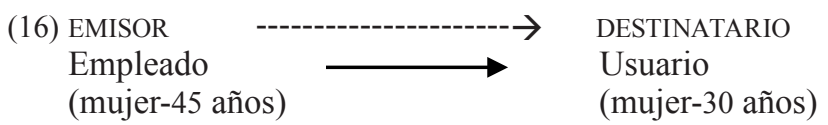

Contexto: Mientras U completa un formulario en una institución pública del ámbito educativo en la que los docentes realizan diversos trámites, E le solicita un dato, luego de acceder a su nombre a través de la documentación presentada por U:

— [E] un número de celular julia?

Como se observa en los fragmentos anteriores, los empleados pueden utilizar el nombre de pila del usuario para apelar a él en la formulación de preguntas o pedidos o, como veremos a continuación, en las instancias de cierre de interacción. Evidentemente, cuando no existe conocimiento previo, este tipo de fórmula de tratamiento nominal de uso vocativo nunca aparece en la instancia de apertura conversacional, justamente porque los interactuantes no se conocen previamente o no se identifican por el nombre. Solo cuando el empleado accede a los datos del usuario tiene la posibilidad de usar su nombre de pila como forma de personalización del discurso institucional. Tal como ha sido estudiado por Rigatuso, esto es lo que también sucede en la interacción comercial de la misma comunidad durante la instancia de pago, 
cuando el empleado tiene acceso al nombre de pila de un cliente no habitual a través de la tarjeta de crédito o el documento de identidad. Estos usos forman parte de una tendencia hacia una cultura de acercamiento, personalización y acortamiento de distancias en el estilo comunicativo gestionado ${ }^{43}$.

También hemos relevado frecuentemente, en boca de empleados de estas instituciones, usos del nombre de pila del usuario con una entonación de pregunta para corroborar su identidad. En esos casos resulta interesante el empleo del nombre de pila en lugar del apellido del usuario como modo de corroboración de su identidad ya que esa elección expresaría la ponderación del acercamiento. A modo de ejemplo, transcribimos el siguiente fragmento de una interacción que tiene lugar en una ventanilla de atención al público de una institución educativa pública de nivel superior:

\section{(17) EMISOR $\quad-------------------\rightarrow \quad$ DESTINATARIO \\ Empleado $\longrightarrow$ Usuario (mujer-45 años) $\longleftarrow$ (mujer-28 años)}

Contexto: Una usuaria de una institución educativa pública de nivel superior se dirige a una ventanilla de atención al público para retirar un certificado que había solicitado previamente. E le solicita datos para encontrar el documento:

- $[\mathrm{E}]$ qué día lo pediste?

- $[\mathrm{U}]$ e:::1 dieciséis

— [E] ((lo busca)) mm buá (.) tu numerito?

- $[\mathrm{U}](($ le dice el número de identificación de alumno))

- [E] andrea? ((mirando la computadora))

- [U] sí

\section{b) Otras fórmulas nominales}

\section{- Usos vocativos:}

Entre las formas nominales registradas en uso vocativo se encuentra la fórmula chicos-as y la forma señor-a, utilizadas para focalizar en el destinatario en la formulación de preguntas o pedidos:
(18) EMISOR Empleado (mujer-32 años)
DESTINATARIO
Usuario (dos mujeres-30 años)

Contexto: Luego de responder una consulta de dos docentes del establecimiento, la empleada de una institución educativa privada de nivel superior les pregunta:

- [E] chicas necesitaban algo más? [recibos de sue::ldo]

— [U] [no: nada más] (.) ya retira:mos
(19) EMISOR Empleado (mujer-55 años)

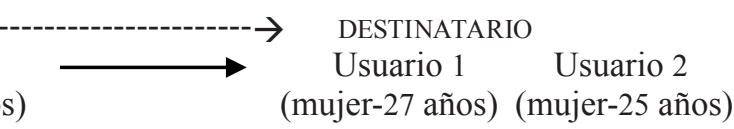

${ }^{43}$ Véase E. M. Rigatuso, «Interacción, variación y cambio: estrategias comunicativas en la interacción comercial del español bonaerense actual». 
Contexto: En una institución pública del ámbito educativo en la que los docentes realizan diversos trámites, $\mathrm{E}$ les pregunta a las usuarias:

- [E] qué título tienen chicas?

En una instancia intermedia de interacción registramos también, en boca de una empleada, el siguiente uso de la fórmula de tratamiento nominal en uso vocativo señora, de poca aparición en el corpus:

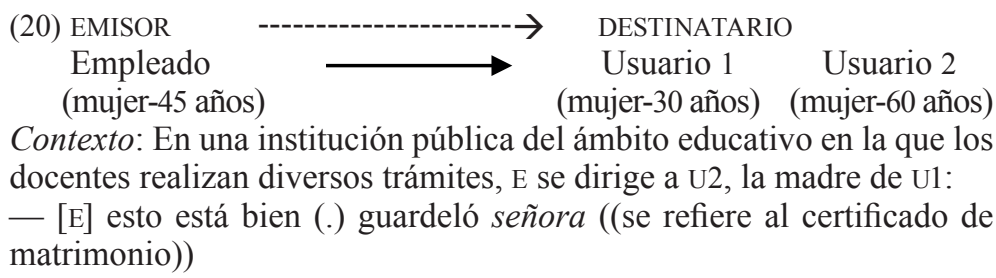

Los usuarios, por su parte, cuando no conocen el nombre de pila del empleado, no suelen emplear fórmulas de tratamiento nominales en uso vocativo en esta instancia de las interacciones. En aquellos casos en que se registra una fórmula nominal, los usuarios utilizan el vocativo chicos-as para destinatarios plurales, o señor-a para empleados de mayor edad, aunque estos usos no resultan muy frecuentes en estos contextos. Sin embargo, en pocas oportunidades, cuando existe conocimiento previo y confianza, además del nombre de pila registramos el uso de la forma che en boca de usuarios. En el siguiente ejemplo la forma es utilizada por un estudiante al dirigirse a una empleada de la ventanilla del departamento donde estudia en una institución educativa pública de nivel superior:
(21) EMISOR
Usuario
(hombre-29 años)
DESTINATARIO
Empleado
(mujer-30 años)

Contexto: Un becario realiza un trámite en una ventanilla del departamento de la institución educativa pública de nivel superior en la que tiene su lugar de trabajo. Mientras firma planillas le dice a E:

- $[\mathrm{U}]$ che (.) te hago una consulta

Otro ejemplo se registra en la misma ventanilla en boca de una docente en interacción con un empleado:
(22) EMISOR
Usuario
DESTINATARIO
(mujer-50 años)
Empleado
(hombre-42 años)

Contexto: U realiza una consulta por la reserva de un aula en una institución educativa pública de nivel superior en la que se desempeña como docente:

— $[\mathrm{U}]$ no te la: capaz que me dieron la de confere:ncias che? 
Tal como señala Rigatuso, «[...] el sistema de tratamientos bonaerenses incluye el uso de la partícula che, que es sentida por los hablantes como un modo de trato, de carácter informal» ${ }^{44}$. Se trata de una forma usada para captar la atención y establecer la interacción ${ }^{45}$. Es probable que los usuarios de los ejemplos transcriptos elijan este tratamiento de carácter informal debido a la relación de confianza que tienen con los empleados, consecuencia de las asiduas consultas y trámites que realizan los estudiantes y docentes en la ventanilla del departamento en el que estudian o desempeñan un cargo docente. En el vínculo empleado/empleado también registramos este uso en coocurrencia con el nombre de pila, por ejemplo, en boca de un empleado de una ventanilla de una institución educativa pública de nivel superior para hacerle un pedido a un empleado de otro sector, con el que tiene una relación de confianza: «marianito: bue:nos días (.) che marianito...».

- Usos referenciales:

Entre los usos referenciales registramos la forma chico-a-os-as utilizada por empleados y usuarios en referencia a distintas personas. En primer lugar, los empleados suelen utilizar esta forma para referirse a los usuarios, tal como ilustran los siguientes ejemplos:

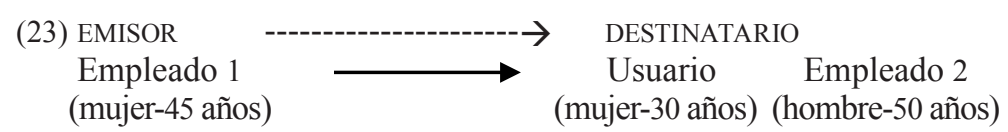

Contexto: En una institución pública del ámbito educativo en la que los docentes realizan diversos trámites, mientras E1 atiende a U bromea con E2:

— [E1] la chica? ((alude a U)) se casó! lo mejor que le pudo pasar a ella ((U se ríe)) mirá nosotros yo llevo veinticinco este año y fede cuánto?

Más adelante agrega:

- [E1] ahí viene mi chica ((alude a otra usuaria, de 30 años, que había atendido antes y adeudaba una planilla)) (.) atendemelá fede tomá ((E2 se queja)) está todo hecho (.) atendémela bien (.) tiene todo le faltaba la planillita fede:
(24) EMISOR
Empleado

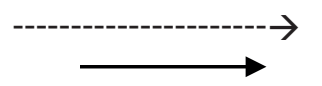
DESTINATARIO
Usuario
(hombre-34 años) (hombre-35 años)

Contexto: Mientras atiende a una usuaria de 30 años, un empleado de una ventanilla de una institución educativa pública de nivel superior se dirige a un usuario que está esperando sus servicios:

— [E] si querés esperar un ratito: termino con la chica y:

${ }^{44}$ E. M. Rigatuso, Fórmulas de tratamiento y familia en el español bonaerense actual, pág. 22.

${ }^{45}$ E. M. Rigatuso, «Dinámica de los tratamientos en la interacción verbal: preparación y apertura conversacionales», pág. 171. 


\section{(25) EMISOR $\quad$--------------------- $\rightarrow$ DESTINATARIO \\ Usuario $\longrightarrow$ Empleado \\ (mujer-29 años) $\longleftarrow$ (mujer-42 años)}

Contexto: En una institución pública del ámbito educativo en la que los docentes realizan diversos trámites, E llama al siguiente usuario de la fila. U se acerca al escritorio y toma asiento:

- [U] hola:

- [E] cómo estás?

- $[\mathrm{U}]$ qué tal?

- [E] ((es))perá que le hago la:

- [U] sí sí

- [E] etiquetita a este chico ((se refiere al usuario anterior, un hombre de 30 años)) y ya: te: (1) te atie:ndo:

También registramos con mucha frecuencia el uso de la forma referencial los-las chicos-as en boca de los empleados para referirse a otros trabajadores de la institución, formas que marcan su pertenencia institucional a través de su discurso, ya que refieren a un grupo particular de empleados de otro sector de la institución. A continuación transcribimos algunos ejemplos de este uso, que también aparece en boca de la usuaria de uno de los fragmentos transcriptos:

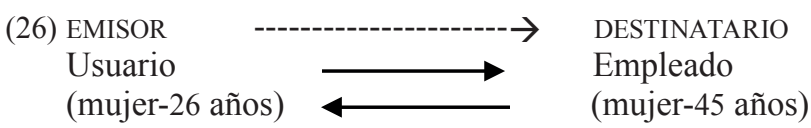

Contexto: Durante una interacción en una institución pública del ámbito educativo en la que los docentes realizan diversos trámites, $\mathrm{U}$ le pregunta a E sobre los datos que debe agregar en una planilla:

- [U] agrego todos estos?

- [E] no me parece que tenés que (.) el número nada más (.) a ver preguntá a las chicas acá viste donde está la ventanita esa:? ((señalando otra oficina))

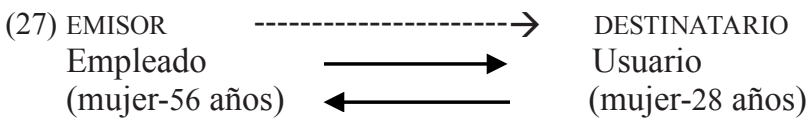

Contexto: En una institución educativa pública de nivel superior, U realiza un reclamo en una ventanilla por un error en el porcentaje de materias que figura en su analítico:

- [E] lo que es porcentaje arriba! con los chicos de allá

- $[\mathrm{U}]$ ah! pregunto arriba?

- [E] e:xacto

- [U] a los chicos que me dan el analítico?

Finalmente, cuando el referencial chicos-as aparece en boca de los docentes usuarios de ventanillas, dicha forma puede hacer referencia a los alumnos, como se observa en el siguiente ejemplo: 


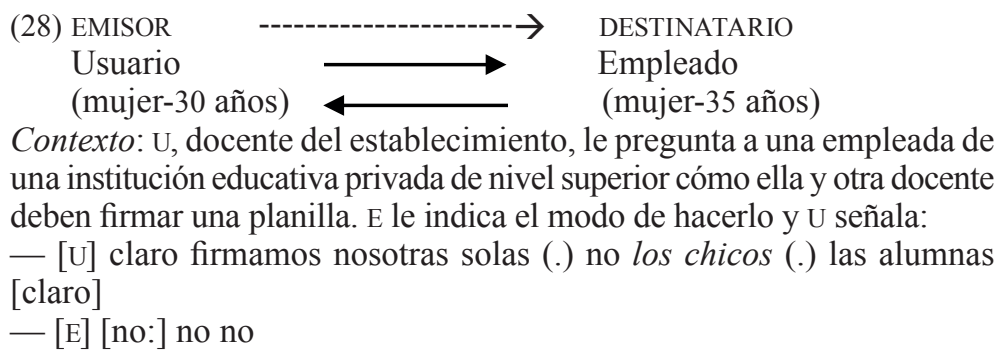

\subsubsection{Instancia de cierre}

En la instancia de cierre de las interacciones también relevamos el uso de tratamientos nominales. Los mismos, aunque no registran mucha frecuencia de uso, pueden ser el nombre de pila o bien otras fórmulas nominales.

a) Nombre de pila

- Conocimiento previo:

En los casos en los que existe conocimiento previo entre empleados y usuarios, el nombre de pila se utiliza acompañando los saludos de despedida y los agradecimientos, como ilustra el siguiente ejemplo:
(29) EMISOR
Empleado
$----------------------\rightarrow \quad$ DESTINATARIO
(hombre-35 años)
Usuario
(mujer-28 años)

Contexto: En una institución educativa pública de nivel superior, una becaria se acerca a la ventanilla del departamento que constituye su lugar de trabajo para realizar una consulta sobre la inscripción a un seminario de posgrado. Al finalizar la misma, E le entrega a U una carpeta que debía retirar:

— [E] acá está

- [U] ah (.) bueno (.) muchas gracias ariel

- [E] tuyo

- [U] nos vemo:s

- [E] chau cintia (.) [hasta luego]

- [U] [cha:u:]

- Ausencia de conocimiento previo:

Cuando no existe conocimiento previo entre los participantes pero el empleado accede al nombre del usuario a través de la computadora o de planillas, en ocasiones lo utiliza en la instancia de conclusión para focalizar en el usuario, como se observa en el ejemplo que transcribimos a continuación:

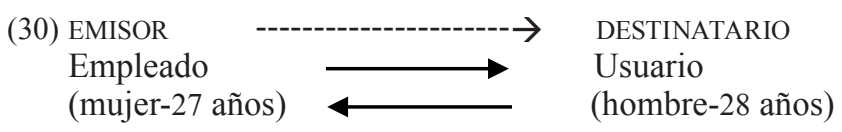


Contexto: En una institución educativa pública de nivel superior, en el momento de finalización del trámite de solicitud del título de grado la empleada le indica al usuario:

- [E] bueno matías (.) si está todo bien cuatro o cinco meses ( ) con tu libreta universitaria ( ) en qué instancia del trámite estás (.) cómo va todo sí?

— [U] listo (.) ustedes me avisan a mí

\section{b) Otras fórmulas nominales}

A lo largo del corpus hemos relevado para destinatarios plurales, el uso vocativo de la forma chicos-as para focalizar en los usuarios, conocidos o desconocidos, en los saludos de cierre en la instancia de terminación y en expresiones que indican la finalización del tema en la instancia de conclusión.

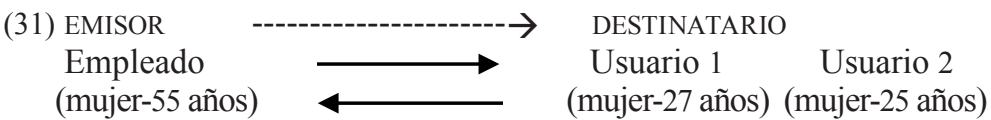

Contexto: En una institución pública del ámbito educativo en la que los docentes realizan diversos trámites, E se dirige a las usuarias, con quienes no existía conocimiento previo, luego de responder a sus consultas:

- [E] listo chicas

- [U1] bueno muchísimas gracias
(32) EMISOR
Empleado
DESTINATARIO
(mujer-60 años)
Usuario
(mujeres-25 años)

Contexto: En una institución pública del ámbito educativo en la que los docentes realizan diversos trámites, luego de responder a la consulta de dos usuarias E les indica dónde continuar el trámite:

- [E] bueno chicas (.) a la segunda puerta a la izquierda chicas
(33) EMISOR
Empleado

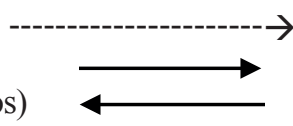
DESTINATARIO
Usuario 1
Usuario 2
(mujer-35 años) (mujer-29 años) (mujer-30 años)
Contexto: En una institución educativa privada de nivel superior, E se dirige a dos docentes del establecimiento que se retiran luego de firmar unas planillas:
- [E] chau [chicas $](($ sonriendo $))$
- [U1] [chau] (.) hasta luego

También registramos en estas instancias de las interacciones el uso de la forma chicos-as en boca de usuarios para dirigirse a empleados/as, como ilustra el siguiente ejemplo, en el que el tratamiento focaliza el agradecimiento en las empleadas: 


\section{(34) EMISOR $\quad$---------------------- $\rightarrow$ DESTINATARIO Usuario $\longrightarrow$ Empleadas (mujer-30 años) $\longleftarrow$ (mujeres-30-35 años)}

Contexto: La usuaria, docente de una institución educativa privada de nivel superior se dirige a las empleadas luego de retirar un certificado:

- $[\mathrm{U}]$ gracias chicas

Finalmente, en la instancia de conclusión de una interacción hemos relevado el empleo de la forma nominal en uso vocativo señorita, que se encuentra en proceso de retracción de su uso en nuestra comunidad en el dominio social para el trato vocativo ${ }^{46}$ :

\section{(35) EMISOR $\quad$--------------------- $\rightarrow \quad$ DESTINATARIO

Empleado $\longrightarrow$ Usuario

(hombre-40 años) (mujer-28 años)

Contexto: En una institución educativa pública de nivel superior E atiende a un usuario que va a sacarse la foto para un trámite. Al concluir el trámite E señala:

— $[\mathrm{E}]$ listo señorita

El análisis de los usos generales de las fórmulas de tratamiento en los distintos puestos de atención al público del dominio de la educación ha puesto de manifiesto que, aunque no resultan de uso muy frecuente en todos los intercambios, en las diferentes instancias de las interacciones en que aparecen, los tratamientos operan como elementos codificadores de cortesía y forman parte, junto con otros factores, de una tendencia a una cultura de acercamiento tal como la relevada en el estilo comunicativo de la interacción comercial de la misma comunidad ${ }^{47}$.

\subsection{Usos específicos de fórmulas de tratamiento en una institución pública del dominio educativo}

A continuación focalizamos concretamente en las fórmulas de tratamiento que hemos relevado en la institución pública del ámbito educativo a la que los docentes se dirigen para realizar diversos trámites vinculados con el ejercicio de la labor docente. Estas son examinadas por separado debido a que se trata de formas de particular uso en dicha institución, que no hemos registrado en las ventanillas de los establecimientos educativos de nivel superior estudiados.

Tal como hemos señalado, Rigatuso se refiere a las fórmulas de tratamiento como «marcadores lingüísticos de relaciones interpersonales de los hablantes

${ }^{46}$ E. M. Rigatuso, «'Señora [...] ¿No tenés más chico?’ Un aspecto de la pragmática de las fórmulas de tratamiento en español bonaerense», pág. 333.

${ }^{47}$ E. M. Rigatuso, «Interacción, variación y cambio: estrategias comunicativas en la interacción comercial del español bonaerense actual». 
— donde rigen las dimensiones de poder y solidaridad ${ }^{48}$ —, y marcadores sintomáticos de identidad...» $\gg^{49}$. La dinámica de las fórmulas de tratamiento, entonces, se vincula estrechamente con las dimensiones de poder y solidaridad propuestas por Brown y Gilman ${ }^{50}$. En tal sentido, como sostiene Rigatuso, los hablantes tienen la posibilidad de elegir entre fórmulas de tratamiento con distintos grados de familiaridad y formalidad, posibilidades cuya combinación «...estructura el sistema a partir de tres alternativas básicas: usos asimétricos (familiar-formal), usos recíprocos o simétricos de confianza (familiar-familiar), y usos recíprocos alejados (formal-formal) $\rangle^{51}$. Cuando predomina el poder en las relaciones, la elección de los tratamientos, tanto pronominales como nominales vocativos y referenciales, se orienta hacia un uso asimétrico. El uso de fórmulas de tratamiento empleadas de manera no recíproca pone en escena una relación vertical y expresa la jerarquía entre los interlocutores ${ }^{52}$.

En cuanto a las pautas de uso, a lo largo de algunas interacciones desarrolladas en la institución en la que se desarrollan trámites vinculados con el desempeño en docencia, observamos un uso asimétrico de fórmulas de tratamiento por parte de las empleadas, quienes utilizan, cuando se dirigen a los usuarios, formas nominales del tipo de madre, mamita, mami, ma, corazón, mi amor, mi vida, querida, niño-a, nena, unidas al pronombre de confianza vos y sus formas verbales correspondientes, y reciben, en cambio, de parte de los usuarios, el pronombre formal usted + sus formas verbales (no suelen utilizar la forma señora en uso vocativo), que constituye la pauta formal para dirigirse a las empleadas. En el modo referencial se articula, en boca de los usuarios, con el trato de cortesía señor-señora. Ocasionalmente también se registra señora + vos, pauta interaccional innovadora del español bonaerense actual ${ }^{53}$. En el aspecto nominal, las fórmulas elegidas por las empleadas corresponden a tres tipos dentro del subsistema correspondiente del español bonaerense, según las categorías establecidas por Rigatuso ${ }^{54}$ : a) términos de parentesco empleados metafóricamente en lo que se denomina usos ficticios ${ }^{55}$ de los términos de parentesco (por ejemplo, mamita), b) términos de amistad, cordialidad y afecto (por ejemplo, corazón, mi amor, mi vida, querida), y c) formas destinadas a niños (por ejemplo, niño-a, nena), correspondientes a los términos sociales de índole general.

${ }_{48}$ R. Brown y A. Gilman, op. cit.

${ }^{49}$ E. M. Rigatuso, «Fórmulas de tratamiento, políticas lingüísticas y actitudes en el español de la Argentina: El caso del español bonaerense», pág. 197.

${ }^{50}$ R. Brown y A. Gilman, op. cit.

${ }^{51}$ E. M. Rigatuso, «'Señora [...] ¿No tenés más chico?’ Un aspecto de la pragmática de las fórmulas de tratamiento en español bonaerense», pág. 302.

${ }^{5}$ B. Gabbiani y I. Madfes (org.), op. cit, pág. 22.

${ }^{53}$ Cf. E. M. Rigatuso, «'Señora [...] ¿No tenés más chico?’ Un aspecto de la pragmática de las fórmulas de tratamiento en español bonaerense» y «Cuestiones de variación lingüística en un sistema de tratamientos del español de la Argentina. El español bonaerense 2: cambios momentáneos de tratamiento pronominal y esquemas innovadores».

${ }^{54}$ E. M. Rigatuso, Fórmulas de tratamiento y familia en el español bonaerense actual, pág. 21.

${ }^{55} \mathrm{~F}$. Braun, op. cit. 
En el conjunto de las formas relevadas, el caso de madre, mamita, mami y $m a$, así como el de otros términos de parentesco, corresponde a un proceso de extensión semántica ${ }^{56}$ que consiste en «... el empleo metafórico de los términos de parentesco a vínculos fuera de la relación original: el llamado uso ficticio de los términos de tratamiento.... ${ }^{57}$. Tal como señala Rigatuso, las formas madre y mamita se usan en el ámbito comercial como tratamientos de cortesía de los vendedores hacia sus clientas, pero mientras que madre es evaluado por los hablantes como neutro, mamita:

[...] dispensado a mujeres jóvenes suele generar en las mismas una actitud de rechazo, por la asociación de este tratamiento con otro empleo extensivo del mismo tratamiento en español bonaerense: su valor para la expresión de piropos en boca de los hombres.... ${ }^{58}$.

A este uso ficticio de términos de parentesco se le suma, en las interacciones analizadas, el empleo de formas metafóricas como corazón, mi amor, mi vida - extensiones semánticas de distintas formas léxicas ${ }^{59}$-, y los tratamientos querida, niño-a y nena, que podrán ser interpretadas por los usuarios como más o menos corteses en ese contexto y con esos destinatarios.

En español bonerense el uso de fórmulas de tratamiento de la índole referida como forma alternativa de trato se encuentra en vinculación con el problema del vacío léxico que ha generado el avance de vos en detrimento de usted, ante la ausencia de otras formas en el sistema para dirigirse a las destinatarias jóvenes en ciertos contextos que acompañen el empleo pronominal de confianza, y el progresivo desuso de la fórmula señorita para el trato social ${ }^{60}$. Al respecto, Rigatuso señala:

Una mirada al sistema de tratamientos nominales vigentes en español bonaerense en la actualidad, en su dinámica operativa interaccional, revela la existencia de vacíos léxicos en el sistema, generados por la ausencia de fórmulas para determinados contextos, situaciones o destinatarios en ciertas variedades de lengua ${ }^{61}$.

En la institución pública del ámbito educativo examinada hemos recogido, en boca de algunas empleadas de entre 55 y 60 años, formas nominales en uso

${ }^{56}$ E. M. Rigatuso, «'Madryn, pasame el apunte’. Aspectos léxico-semánticos del vocativo en español bonaerense actual», pág. 376.

${ }^{57}$ E. M. Rigatuso, «Cortesía, tratamientos e identidad cultural en encuentros de servicio en español bonaerense», pág. 165 .

${ }^{58}$ E. M. Rigatuso, loc. cit., pág. 167.

${ }^{59}$ E. M. Rigatuso, «'Madryn, pasame el apunte'. Aspectos léxico-semánticos del vocativo en español bonaerense actual», pág. 377.

${ }^{60}$ E. M. Rigatuso, «'Señora [...] ¿No tenés más chico?’ Un aspecto de la pragmática de las fórmulas de tratamiento en español bonaerense», pág. 333.

${ }^{61}$ E. M. Rigatuso, loc. cit., pág. 324. 
vocativo tales como niño- $a$, nena, madre, mamita, entre otras que analizamos a continuación en vinculación con su valor pragmático y las percepciones de los usuarios acerca de estos usos. En tal sentido, como vemos en los siguientes ejemplos, las fórmulas de este tipo suelen aparecer, como tratamientos corteses, para apelar al usuario en la formulación de preguntas, pedidos, negaciones y en las instancias de apertura y de cierre de interacción:

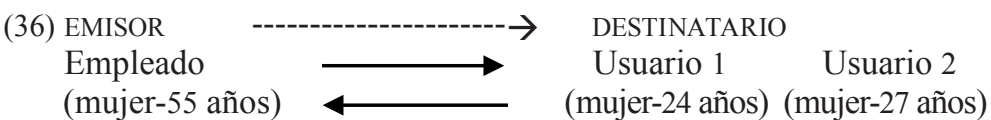

Contexto: En una institución pública del ámbito educativo en la que los docentes realizan diversos trámites, E se dirige a U1 en los siguientes términos:

- [E] está todo mamita?

- [U1] no todavía no

$$
[\ldots]
$$

- [U1] licenciada en psicopedagogía

— [E] y aparte qué más (.) madre?

- [U1] psicopedagoga

$$
\text { [...] }
$$

— [E] el folio nena ((tempo acelerado)) ((se lo da)) listo chicas (.) tomaron nota de esta página?
(37) EMISOR
Empleado

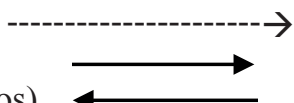
DESTINATARIO
Usuario
(mujer-58 años)
(mujer-28 años)

Contexto: $\mathrm{U}$ ingresa a una oficina de una institución pública del ámbito educativo para realizar una consulta y la atiende una empleada desde su escritorio:

- [E] niña?

— [U] hola! qué tal? ehh una consulta (.) hoy atienden para presentar la planilla XXXX?

- $[\mathrm{E}]$ los jueves no mamita

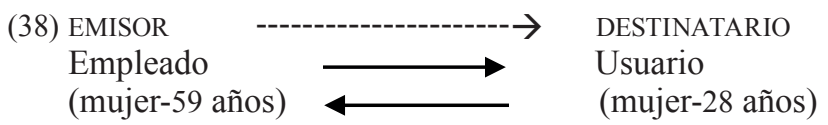

Contexto: Una empleada de una institución pública del ámbito educativo en la que los docentes realizan diversos trámites le indica a U los pasos a seguir:

— [E] esto (.) andá para allá y que lo: eh? ((está indicando que vaya a una oficina para que le firmen la documentación))

- $[\mathrm{U}]$ bueno

- [E] listo niña

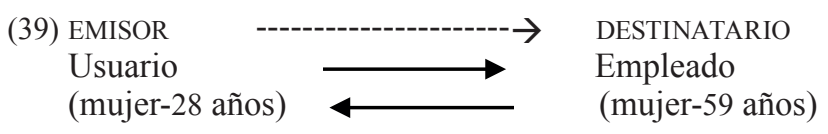


Contexto: En una institución pública del ámbito educativo en la que los docentes realizan diversos trámites, $\mathrm{U}$ debe regresar a la ventanilla en la que fue atendida previamente ya que en la segunda oficina a la que se dirigió por el trámite le informaron que faltó un dato que debían anotar en la primera ventanilla:

— [U] disculpe (.) le faltó la fecha me dijo el señor ((se refiere a un empleado de 50 años))

- [E] ah (.) vení corazón (.) vení (1) a veces quedan pegados ((le agrega la fecha)) decile (1) decile así (.) DIJO ANA QUE LA PRÓXIMA VEZ LA PONGA ÉL (.) decile (.) en serio te digo eh? porque así no las hace venir

\section{(40) EMISOR $\quad$--------------------- $\rightarrow \quad$ DESTINATARIO \\ Empleado $\longrightarrow$ Usuario \\ (mujer-60 años) $\longleftarrow$ (mujer-30 años)}

Contexto: Una usuaria de una institución pública del ámbito educativo le informa a $\mathrm{E}$ cuál es el trámite que debe realizar y E le indica qué documentación necesita:

- [E] bueno! del secundario para adelante todo corazón y el DNI!

$[\ldots]$

— [U] igual lo tra:je por las dudas

— [E] no! si vos decís que:: (x) ingresado no hay problema (.) el DNI niña

— [E] ((finalizando el trámite)) bue:no niña ((le devuelve la documentación)) segunda puerta a la izquierda te firman

En el contexto sociocultural estudiado, el empleo de este tipo de formas suscita particular interés debido al valor pragmático que adquieren en algunos casos relevados, como los que analizamos a continuación, ya no como elementos codificadores de cortesía sino como elementos codificadores de descortesía, desde la perspectiva del usuario. Las fórmulas de trato familiar registradas en los siguientes casos analizados, también recogidas por Placencia en su estudio de las interacciones en puestos de atención al público de carácter institucional en Ecuador ${ }^{62}$, son utilizadas por algunas empleadas cuando rehúsan algo a los usuarios o les hacen un pedido, acompañando una negación, cuando pretenden acelerar el trámite o bien, la mayoría de las veces, cuando les aclaran algo que, a su criterio, es evidente, expresando así impaciencia y fastidio, actitud que se pone en evidencia en el tono de voz, el volumen, el tempo y los gestos que acompañan la emisión de la fórmula de tratamiento. A continuación transcribimos algunos ejemplos:

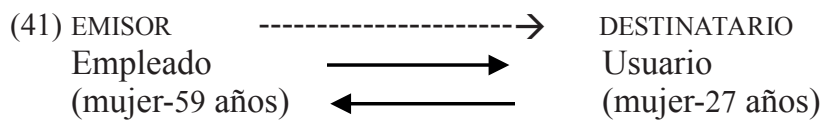

${ }^{62}$ M. E. Placencia, op. cit. 
Contexto: La usuaria se acerca al escritorio para registrar su título universitario. La empleada le pide los títulos:

- [E] ...título (.) DNI y títulos anteriores

- $[\mathrm{U}]$ títulos anteriores?

- [E] secundario corazón ((seria, tempo acelerado))

- [U] ahh ((lamentándose)) no lo traje

- [E] a ver si está (x) ((se aleja a la computadora)) (15) no niña vos no tenés nada acá ((seria, tono brusco, tempo acelerado))

\section{(42) EMISOR}

Usuario

(mujer-27 años)

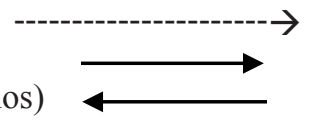

DESTINATARIO

Empleado

(mujer-55 años)

Contexto: La empleada les indica a $\mathrm{U}$ y a su acompañante que deben anotarse en un listado. U pregunta:

- $[\mathrm{U}]$ pero aunque nos hayamos anotado el año pasado:?

- [E] ((seria, gesto de desaprobación, tempo lento)) es que todos los años se tienen que anotar corazón
(43) EMISOR

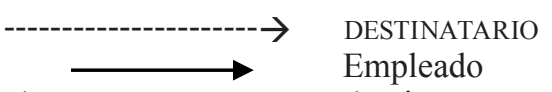
Usuario
Empleado
(mujer-24 años)
(mujer-55 años)

Contexto: E le indica a U que debe foliar las hojas que entrega y le dice que debe escribir F1 y F2, pero le señala la misma hoja. U pregunta:

- $[\mathrm{U}]$ todo $\mathrm{F} 1 \mathrm{es}$ ?

- [E] no:: mi amor ((con tono de fastidio)) esta es uno (.) la otra es dos

- $[\mathrm{U}]$ sí pero: es foja uno:?

- [E] no (.) no mi amor mi amor (.) esto es foja uno (.) esto es foja dos ((tono que indica impaciencia))
(44) EMISOR
Usuario
(mujer-24 años)
DESTINATARIO
Empleado
(mujer-55 años)

Contexto: U necesita la ayuda de E porque no sabe a qué se refieren ciertas preguntas del formulario que debe completar:

- [U] hay algo que acá no completé por ejemplo ((leyendo)) posee cambio de funciones?

- [E] no: ((con tono de fastidio y volumen de voz bajo)) no mamita (.) estás en la dirección general de escuelas vos? [no]

- $[\mathrm{U}][\mathrm{no}:]$

— [E] ((volumen más alto)) aptitud psicofísica? no (.) jubilado? no ((se lo marca bruscamente en la planilla))

- [U] okey

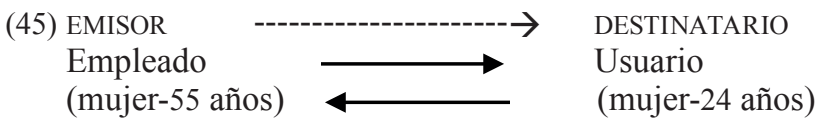

Contexto: $\mathrm{E}$ le pide el folio a $\mathrm{U}$ en los siguientes términos:

— [E] el folio nena ((tempo acelerado)) 


$\begin{array}{lll}\text { (46) } \begin{array}{l}\text { EMISOR } \\ \text { Empleado } \\ \text { (mujer-55 años) }\end{array} & \begin{array}{l}\text { DESTINATARIO } \\ \text { Usuario } \\ \text { (mujer-24 años) }\end{array}\end{array}$

Contexto: Mientras U termina de completar el formulario E parece pretender continuar con el trámite sin perder tiempo:

— [E] bueno (.) ahora mami (.) profesora en le:tras ((tono de impaciencia))

(47) EMISOR Usuario (mujer-27 años)

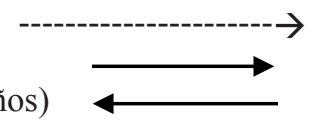

\author{
DESTINATARIO \\ Empleado \\ (mujer-55 años)
}

Contexto: U se confunde la fecha de inscripción de los listados:

- $[\mathrm{U}]$ a mí siempre me dijeron que si yo me anotaba en agosto estaba anotada para el año siguiente

- [E] no pero mi amor (.) a ver (.) esto es IN FI NE
(48) EMISOR

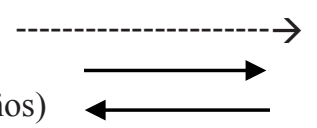
DESTINATARIO
Usuario
Empleado
(mujer-26 años)
(mujer-59 años)

Contexto: La usuaria y su acompañante están por llegar a la fila cuando la empleada avisa que va a interrumpir la fila por estar próximos al horario de cierre. Las usuarias que se acercan a la cola después del corte deciden ir a preguntarle a E si pueden hacer la fila porque son las 11.59 o 12 en punto. E rechaza el pedido y $\mathrm{U}$ insiste:

- $[\mathrm{U}]$ es que en realidad son las doce (.) es que yo trabajo (emisión que no se entiende)

— [E] MANDÁ A A:LGUIEN CORAZÓN (.) ((sin mirarla)) PODÉS MANDAR A CUALQUIER PERSONA MI VIDA: ((tono soberbio y desafiante))
(49) EMISOR
Empleado

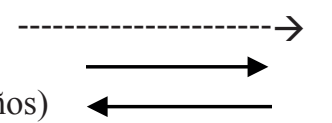
DESTINATARIOO
Usuario
(mujer-59 años)
(hombre-38 años)

Contexto: $\mathrm{U}$ va a registrar cursos y títulos habilitantes para ejercer en docencia pero E le rechaza toda la documentación porque le faltan los originales:

— [E] Y ES FOTOCOPIA QUE NO TE CORRE (1) ACÁ HAY QUE TRAER TODO POR ORIGINAL ((enojada, tempo acelerado))

— [U] está:: avalada=

— $[\mathrm{E}]=$ NO IMPO:RTA: ((gesto con los hombros)) (1) O-RIGINAL NIÑO

Luego de rechazar toda la documentación, E le dice a $\mathrm{U}$ que vuelva con todo lo que le pidió:

- [U] y mañana atienden?

- [E] sí creo que sí no sé (.) depende qué resuelven ((se refiere al paro, se dirige a la siguiente usuaria en la fila, una mujer de 28 años)) dale corazón (.) vamos querida: ((tempo acelerado, gesto con la mano para que se apure)) 
Si bien las fórmulas de tratamiento de este tipo podrían ser catalogadas como corteses ya que, como señala Placencia ${ }^{63}$, en el contexto de la familia y las amistades demuestran familiaridad y afecto, su uso en contextos formales como el que estudiamos, en donde se pone en escena una relación vertical, puede resultar abusivo debido a que se dirigen a desconocidos y se emplean de manera asimétrica. De hecho, es así como lo interpretan los usuarios entrevistados por Placencia, como un «abuso de confianza». Siguiendo a Rigatuso, se trataría de un caso de «cortesía funcionando como trato no cortés, poco cortés o descortesía por diferencias en la percepción de hablante y de destinatario de qué es cortés en un contexto concreto de interacción» ${ }^{64}$. Como señala la investigadora, tal sería el caso del uso, por parte de vendedores en la interacción comercial en español bonaerense, de fórmulas como mi vida, mi amor, negri, gordi, intentando manifestar cortesía, cuando en realidad esas formas son decodificadas negativamente como una invasión a la intimidad, ya que las emplean «...hablantes no autorizados a utilizar esos tratamientos con esos destinatarios en dichos contextos $»^{65}$. Tal como señala Sánchez Lanza acerca de los usos de este tipo, también registrados por la investigadora en puestos de atención al público del ámbito de la salud, «la entonación determinará si deben tomarse como signo de acercamiento o como abuso de confianza y, por consiguiente, agresivas $\rangle^{66}$. En tal sentido, en entrevistas que realizamos previamente ${ }^{67} \mathrm{y}$ en los cuestionarios de hábitos sociales aplicados para conocer la percepción de los usuarios acerca del trato (des)cortés en la atención al público en instituciones y en la vida cotidiana, hemos recogido comentarios de rechazo hacia estas fórmulas de tratamiento, que fueron calificadas como descorteses en determinados contextos. Por ejemplo, una usuaria de instituciones públicas que entrevistamos expresó lo siguiente:

${ }^{63}$ M. E. Placencia, op cit., pág. 200.

${ }^{64}$ E. M. Rigatuso, “"¿Y vos por qué me tratás de usted?” Fórmulas de tratamiento y cortesía lingüística en español bonaerense actual», pág. 14.

${ }^{65}$ E. M. Rigatuso, loc. cit. En su trabajo «¿Cortesías en pugna? Fórmulas de tratamiento nominales y (des)cortesía verbal en encuentros de servicio comerciales del español bonaerense actual», Rigatuso refiere a los usos de formas nominales innovadoras en la interacción comercial que pueden interpretarse como invasivas o descorteses, lo que plantea un conflicto entre la cortesía codificada e interpretada y el llamado efecto de cortesía. Asimismo, la investigadora se centra en la percepción de los hablantes a partir de entrevistas y de la aplicación de test de hábitos sociales.

${ }^{66}$ C. Sánchez Lanza, «El discurso de la cortesía en puestos de atención al público en la Argentina (instituciones de salud pública y bienestar social)», en D. Bravo (ed.), Actas del Primer coloquio del programa EDICE, pág. 337.

${ }^{67}$ Véase G. Julián, «Percepciones de la (des)cortesía en instituciones de atención al público en el español bonaerense: la comunidad de Bahía Blanca», en V. Castel y L. Cubo de Severino (eds.), La renovación de la palabra en el bicentenario de la Argentina. Los colores de la mirada lingüistica, Editorial FFyL, UNCuyo, Mendoza, 2010, págs. 681-691. 
Usuaria: mujer-45 años — nivel educacional medio

- $[\mathrm{U}]$... también me molesta si te tratan con familiaridad y te dicen mami::ta (.) mi amo:r

Incluso, al solicitar ejemplos de descortesía en el cuestionario de hábitos sociales, un hablante refirió como ejemplo el caso de una profesora que trató de mi amor con «tono soberbio» a un alumno por no entender algo, mientras que otra usuaria se refirió al empleo de tales fórmulas en los siguientes términos:

- Los casos en que un empleado/a de alguno de los organismos antes citados, trata a su intelocutor/interlocutora más joven con términos como «nena», «querida», «corazón», entre otros (en estos caso, considero que son importantes los elementos «paratextuales» de ese intercambio) ${ }^{68}$.

Asimismo, en la interacción cotidiana hemos recogido comentarios metalingüísticos de hablantes de la comunidad que expresan su rechazo hacia este tipo de fórmulas, como por ejemplo un hombre de 56 años que sostuvo:

- A mí me molesta que alguien que no me conoce me diga papá, corazón, mi amor, no, si me dicen papá salto como un loco y le digo ¿qué me venís a decir papá?, parece que te están forreando. Tiene que ver también con el tono que te lo dicen ${ }^{69}$.

Como veremos a continuación, los hablantes con los que realizamos la experiencia de evaluación de las grabaciones también expresan su rechazo hacia estas fórmulas de tratamiento cuando son emitidas por desconocidos. Así, por ejemplo, una de las hablantes, de 26 años, señaló:

- A mí no me gusta que me digan mi amor, corazón, mamita, ni querida, ni nena, me molesta cuando me lo dice alguien con quien no tengo vínculo afectivo, lo mismo con mi cielo, mi vida, gordi.

Esta evaluación negativa se pondera aún más cuando estas formas aparecen en instancias discursivas de carácter poco cortés. Así, en este último grupo de ejemplos que analizamos, las fórmulas de trato familiar podrían interpretarse como formas afectuosas vinculadas a la diferencia de edad entre empleadas y usuarios, o como fórmulas con función atenuante cuando acompañan pedidos o negaciones; sin embargo, el tono de voz, que muchas veces expresa fastidio,

${ }^{68}$ Cuando incluimos respuestas de los informantes a los tests de hábitos sociales mantenemos la ortografía y puntuación original de las mismas en la producción escrita de los hablantes.

${ }^{69}$ Sánchez Lanza señala que el uso del vocativo papá en los contextos institucionales que estudia «se percibe casi siempre como abusivo o irónico, aunque también su interpretación estará supeditada al tono de voz empleado»(D. Bravo, Actas del Primer coloquio del programa EDICE, pág. 338). 
el volumen, el tempo de las emisiones, y la repetición de las fórmulas (no (.) no mi amor mi amor...), sumado a la evaluación negativa por parte de los hablantes de la comunidad sobre este tipo de fórmulas de tratamiento en ciertos contextos de uso, ponen de manifiesto que probablemente su empleo no pueda interpretarse precisamente como cortés, y resulta dudosa incluso, en muchos de estos casos, la intención cortés del emisor. En tal sentido, nos pareció interesante conocer la interpretación de diversos hablantes de la comunidad acerca de estos usos, para lo cual, siguiendo la propuesta metodológica de Gumperz ${ }^{70}$, les presentamos el conjunto de fragmentos de las grabaciones que citamos más arriba con el fin de que ellos actúen como jueces o evaluadores de dichas interacciones. Los hablantes que participaron de esta experiencia coincidieron en señalar que las fórmulas de tratamiento que usan las empleadas en su mayoría son descorteses o no corteses en ese contexto y las rechazan. Según su apreciación, dichas formas dan muestra de impaciencia, fastidio, superioridad. Señalan asimismo que, mediante esos usos, parecería que las empleadas no se dirigen a profesionales sino a niños o a gente que no entiende, asociando así el empleo de estas formas con el modo de hablar que usan los adultos cuando se dirigen a los niños, que consideran inapropiado en ese contexto y con esos destinatarios. Además, destacan que mediante dichas fórmulas las empleadas se posicionan en un lugar de mayor poder, ubicando a los usuarios en una posición de inferioridad. Asimismo, en su interpretación tienen en cuenta el tono de voz, aspecto que en algunos casos refuerza la interpretación de las emisiones como descorteses y en otros permite evaluaciones más positivas. A continuación transcribimos algunas interpretaciones de los fragmentos de las grabaciones correspondientes a los ejemplos anteriores:

FRAGMENTO (41):

- La menosprecia por no saber lo que es títulos anteriores. No es cortés, con corazón la quiere hacer sentir inferior y se quiere ubicar ella en un lugar más alto.

FRAGMENTO (42):

- Corazón es descortés por completo, parece que le habla a una criatura, a una persona que no entiende, no como a un adulto, a un profesional...

- La está tratando de estúpida, lo dice con un tono como cansada.

- Por el tono parece que se lo dice más o menos bien, pero cansada de explicar siempre lo mismo.

FRAGMENTO (43):

- Perdió la paciencia la mina, mi amor es descortés, el tono es descortés. A mí no me gusta que me digan mi amor, corazón, mamita, ni querida,

${ }^{70}$ J. Gumperz (ed.), Discourse strategies. 
ni nena, me molesta cuando me lo dice alguien con quien no tengo vínculo afectivo, lo mismo con mi cielo, mi vida, gordi.

— ...con mi amor la deliró, como diciendo «¿qué parte no entendés?»

\section{FRAGMENTO (44):}

- La reta en vez de darle una explicación, como si ella tuviera la obligación de saber qué tiene que poner en el formulario. Le dice mamita por no insultarla, con un tono irritable, se cansa de explicarle algo que ella piensa que lo tiene que saber.

— La trata como a una pobre imbécil, está fastidiada.

- Mamita se lo dice burlándose.

FRAGMENTO (45):

— Diciéndole nena la menosprecia, está re cansada.

FRAGMENTO (47):

- Mi amor es descortés porque lo dice con énfasis y dice in-fi-ne deletreando, sin nada de paciencia.

— Le habla como tontita, le dice mi amor, es descortés, no soporta que alguien no le entienda.

- Hasta mi amor se lo dice bien, pero cuando le dice a ver ya se enciende, se calienta.

FRAGMENTO (48):

- Te choca más que le diga corazón y mi vida porque parece que se está burlando, me resulta falso.

\section{FRAGMENTO (49):}

- Le dice niño y corazón a él, un tipo de treinta y pico de años, no es un nene para decirle corazón.

- Al decirle niño al hombre parece como que ella se ubica en otro lugar, en un lugar de superioridad, como que el otro siempre es menos. - Cuando le dice dale corazón, vamos querida la apura a la usuaria, que no tardaba porque estaba ahí, en realidad no tenía que apurarse porque la chica la estaba esperando a la empleada. Encima la empleada no la saluda, y cuando le dice corazón y querida me choca.

- Cuando apura a la chica es para que el chico se vaya, y a ella le dice corazón y querida pero las usa sobrándola, es despectivo.

Como se puede observar a partir de los fragmentos transcriptos de interacciones espontáneas y de las evaluaciones de los hablantes, es posible inferir que las empleadas parecen considerar que las dudas de los usuarios no son válidas, por lo que responden con un tono que indica que esa información constituye una obviedad, y acompañan sus respuestas con las fórmulas de tratamiento propias del trato familiar, que adquieren en estas situaciones comunicativas valor peculiar, ya que connotan superioridad, fastidio e ironía. Así, las empleadas 
se ubican en el polo de mayor poder por ser las poseedoras de ese saber del que carecen los usuarios. De hecho, se trata de un contexto en el que algunos empleados pueden asumir el rol de porteros ${ }^{71}$ de la institución, ya que son los encargados de garantizar la concreción de los trámites para el acceso del usuario al ejercicio de la labor docente.

\section{Conclusiones}

A lo largo de este trabajo hemos examinado las diferentes fórmulas de tratamiento nominales de tipo vocativo y referencial, así como las pronominales, utilizadas en las interacciones desarrolladas en las instituciones del ámbito de la educación seleccionadas. En tal sentido, clasificamos las fórmulas de tipo nominal de acuerdo con los siguientes tipos dentro del subsistema correspondiente del español bonaerense, según las categorías establecidas por Rigatuso ${ }^{72}$ : a) nombres de pila, b) términos de parentesco empleados metafóricamente en lo que se denomina usos ficticios de los términos de parentesco (por ejemplo, madre, mamita, $m a$ ), c) términos de amistad, cordialidad y afecto (por ejemplo, corazón, mi amor, mi vida, querida), y d) términos sociales de índole general: formas destinadas a niños (por ejemplo, chicos-as, niño-a, nena) y destinadas a adultos (por ejemplo, señor, señora, señorita, muchacho). Asimismo, hemos organizado los distintos usos de acuerdo con la instancia de la interacción en la que tienen lugar.

A partir del análisis advertimos que predomina la ausencia de fórmulas de tratamiento nominales en estas interacciones. Sin embargo, cuando se usan fórmulas de tratamiento, en todas las instancias de los intercambios predomina ampliamente el uso del nombre de pila en boca de empleados y de usuarios, especialmente porque en muchas de estas interacciones existe conocimiento previo entre participantes ${ }^{73}$. El uso del nombre de pila del interlocutor en las instituciones estudiadas se orienta hacia la personalización del discurso institucional, el reconocimiento y la focalización del destinatario, y forma parte de una tendencia, que ha sido registrada por Rigatuso en sus estudios sobre la interacción comercial de la misma comunidad, hacia una cultura de acercamiento, personalización y acortamiento de distancias ${ }^{74}$.

${ }^{71}$ Véase G. Prego Vázquez, «Los recursos interaccionales del poder como mecanismos de negociación de identidades profesionales», Revista Internacional de Lingüística Iberoamericana, V, 1 (9), 2007, págs. 111-124

72 E. M. Rigatuso, Fórmulas de tratamiento y familia en el español bonaerense actual, pág. 21.

${ }^{73}$ Cf. G. Julián, «Usos del nombre de pila en puestos de atención al público en español bonaerense», en R. Bein y E. M. Rigatuso (eds.), Asuntos de Sociolingüística y Análisis del Discurso, Editorial de la Universidad Nacional del Sur, Ediuns y SAEL, Bahía Blanca 2017, págs. 57-68.

${ }^{74}$ E. M. Rigatuso, «Interacción, variación y cambio: estrategias comunicativas en la interacción comercial del español bonaerense actual». 
Resulta pertinente destacar el valor de la presencia de alguna fórmula de tratamiento nominal frente a su ausencia en estos intercambios de tipo institucional, caracterizados con frecuencia por la impersonalidad. En tal sentido, especialmente en lo que hace al uso del nombre de pila, este aspecto de la investigación pone en consideración uno de los usos que orientan la interacción institucional hacia un estilo comunicativo que plantea una relación «más personal y menos institucionalizada» ${ }^{75}$, promoviendo la afiliación ${ }^{76}$ y el acercamiento entre empleados y usuarios.

Las fórmulas de tratamiento utilizadas en las distintas instancias conversacionales contribuyen generalmente a la producción de discursos de cortesía y de acercamiento. Sin embargo, en el análisis de tales fórmulas, nos hemos detenido particularmente, por el interés que suscita, en el uso vocativo de ciertas fórmulas de trato familiar que fueron relevadas solo en una de las instituciones consideradas en nuestra investigación (por ejemplo, mamita, mi amor, mi vida, querida, entre otras), ya que se trata de fórmulas que en algunas interacciones adquieren un valor pragmático particular ya no como elementos codificadores de cortesía sino como elementos codificadores de descortesía. Dichas fórmulas han sido analizadas en relación con las evaluaciones, generalmente negativas, que tienen los usuarios acerca de tales usos, evaluaciones que nos han permitido corroborar nuestras propias interpretaciones al respecto.

En cuanto al funcionamiento de las variables extralingüísticas, la variable sexo ha condicionado variación en la producción de algunas fórmulas de tratamiento, como las que analizamos como usos específicos de una institución en el último apartado, producidas por empleadas mujeres generalmente hacia usuarias también mujeres. La variable edad, como hemos advertido, ha resultado también operativa en el análisis en lo que respecta a la elección de ciertas fórmulas. Sin embargo, no registramos diferencias en cuanto a la variable institución pública / institución privada. Por su parte, la relación existente entre los hablantes, la frecuencia de trato y el conocimiento previo condicionan variación en la elección de fórmulas de tratamiento.

Como línea de continuación de esta investigación, consideramos la importancia de seguir profundizando, tal como venimos haciendo, en el análisis de los diversos factores sociales que intervienen en la elección de las distintas fórmulas de tratamiento o en la preferencia por no utilizarlas, vinculando el uso con las percepciones de empleados y usuarios en tal sentido, en particular a partir de la aplicación de entrevistas que releven la percepción de los hablantes sobre sus elecciones lingüísticas.

75 G. Prego Vázquez, op. cit., pág. 119.

${ }^{7}$ D. Bravo, «Actividades de cortesía, imagen social y contextos socioculturales: una introducción». 